\title{
Blanca Susana Guevara Werlang (15/10/1955-15/11/2013): Um Pouco da História
}

\author{
Clarissa Marceli Trentini ${ }^{1}$ \\ ${ }^{1}$ Universidade Federal do Rio Grande do Sul, \\ RS, Brasil. \\ Margareth da Silva Oliveira² \\ ${ }^{2}$ Pontifícia Universidade Católica do Rio Grande do \\ Sul, RS, Brasil.
}

\author{
Samantha Dubugras Sá ${ }^{2}$ \\ ${ }^{2}$ Pontifícia Universidade Católica do Rio Grande do \\ Sul, RS, Brasil. \\ Irani Iracema de Lima Argimon ${ }^{2}$ \\ ${ }^{2}$ Pontifícia Universidade Católica do Rio Grande do \\ Sul, RS, Brasil.
}

Resumo: Este artigo tem como objetivo revisitar os feitos e homenagear a professora doutora Blanca Susana Guevara Werlang, cinco anos após seu falecimento. Trata-se de uma importante figura na área da avaliação psicológica e em assuntos ligados à prevenção do suicídio, cujo legado se colhe ainda nos tempos atuais. Sua expressiva e relevante produção abarca principalmente temas ligados ao desenvolvimento e adaptação de instrumentos de avaliação psicológica, nas áreas de intervenção clínica e comportamentos violentos. Blanca foi Bolsista Produtividade do CNPq, Professora Titular da Faculdade de Psicologia da Pontifícia Universidade Católica do Rio Grande do Sul e integrou a Comissão Consultiva em Avaliação Psicológica do Conselho Federal de Psicologia de 2005 até seu falecimento, no ano de 2013.

Palavras-chave: Biografia; Avaliação Psicológica, Prevenção do Suicídio.

\section{Blanca Susana Guevara Werlang (15/10/1955-15/11/2013): A Little Bit of History}

\begin{abstract}
This article aims to review the achievements and to honor Professor Blanca Susana Guevara Werlang, five years after her death. She was an important figure in the area of psychological evaluation and in matters related to suicide prevention, and her legacy is still current. Her expressive and relevant production covers topics related to the development of instruments of psychological evaluation and areas of clinical intervention and violent behavior. Blanca was Professor of Psychology at the Pontifícia Universidade Católica do Rio Grande do Sul and joined the Committee of Psychology of the Council of Psychology from 2005 until her death in 2013.
\end{abstract}

Keywords: Biography; Psychological Assessment, Suicide Prevention.

\section{Blanca Susana Guevara Werlang (15/10/1955-15/11/2013): Un Poco de la Historia}

Resumen: Este artículo tiene como objetivo revisar los hechos y homenajear a la profesora doctora Blanca Susana Guevara Werlang, cinco años después de su fallecimiento. Se trata de una importante figura en el área de la evaluación psicológica y en asuntos relacionados a la prevención del suicidio, cuyo legado sigue siendo un tema actual. Su expresiva y relevante producción abarca principalmente temas vinculados al desarrollo y adaptación de instrumentos de evaluación psicológica, en las áreas de intervención clínica y comportamiento violento. Blanca fue Becaria de Productividad del CNPq, Profesora Titular de la Facultad de Psicología de la Pontifícia Universidad Católica de Rio Grande do Sul e integró la Comisión Consultiva en Evaluación Psicológica del Consejo de Psicología de 2005 hasta su fallecimiento en el año 2013.

Palabras clave: Biografia; Evaluación Psicológica, Prevención del Suicidio. 
Aos 15 dias do mês de outubro de 1955 nascia, na cidade de Montevidéu (Uruguai), Blanca Susana Guevara Werlang ou Blanquita, como carinhosamente os amigos a chamavam. Coincidência ou não, anos depois ela viria a comemorar seu aniversário junto ao dia do professor no Brasil. No Uruguai essa data é comemorada no dia 22 de setembro.

Blanca fez graduação em Psicologia pelo Instituto de Filosofia, Ciências e Letras (IFCL) de Montevidéu, Uruguai, tendo se formado no ano de 1979. Durante a faculdade, já formada em História, lecionava em uma escola, ministrando aulas para os anos iniciais do hoje chamado Ensino Fundamental. Sua graduação era uma parceria entre o IFCL e a Pontifícia Universidade Católica do Rio Grande do Sul (PUC-RS). Por conta disso, dois anos antes de se graduar no Uruguai, Blanca e uma amiga, colega de faculdade, vieram a Porto Alegre (RS) trazer documentos necessários para a titulação pela PUC-RS e validação do diploma junto à Universidade Federal do Rio Grande do Sul (UFRGS). Tal feito era indispensável para o título de Psicóloga no Uruguai. Isso ocorreu em meados de setembro de 1977.

Na ocasião, Blanca e sua amiga se hospedaram no Centro Histórico de Porto Alegre, no Hotel Palácio, situado próximo à Santa Casa de Misericórdia. Em uma das suas andanças por Porto Alegre, Blanca e sua amiga foram abordadas, na rua, por dois rapazes. Um deles era Airton Mazzuca Werlang, moço simpático, de sorriso fácil, que conquistou o coração de Blanca. A partir de então os dois namoraram por três anos, na ponte aérea Porto Alegre-Montevidéu. Em 1980 veio definitivamente para Porto Alegre para casar-se com Airton.

Blanca era filha única e seus pais permaneceram no Uruguai até 1988 quando vieram estar junto à filha em Porto Alegre. Frutos do seu casamento nasceram Héctor em 1982 e Frederico em 1986. Todos fanáticos pelo Grêmio Foot-ball Porto-Alegrense, Blanca não perdia a oportunidade de uma boa piada envolvendo as benesses de seu clube de preferência. Adorava viajar e, entre essas viagens, muitas foram a importantes congressos nacionais e internacionais. Em suas breves fugidas para descansar, bem como em boa parte dos verões, passava em sua casa na praia de Atlântida, RS, onde recebia os amigos com a sua especialidade, Pasqualina de bacon com maçã.

De estatura baixa e caminhar "curtinho", ela preservava seu sotaque uruguaio, sendo incapaz de pronunciar a letra "V", substituindo-a pelo "B" em todas as ocasiões. Nessa mesma linha, sempre que era preciso escrever uma palavra com "Z" assegurava-se perguntando: “É 'Z' de Zorro"? Blanca não deixava de lado suas opiniões. Tratava-se de uma figura interessante, de presença marcante, afetiva e de uma retidão acima de tudo. Não há quem não se lembre dela por essa característica.

Assim que chegou ao Brasil começou e concluiu um curso de especialização em Educação Psicomotora pela Faculdade Porto-Alegrense de Educação, Ciências e Letras - FAPA (1981) e iniciou seu trabalho como Psicóloga Clínica em consultório particular. Seu primeiro consultório foi na Avenida Salgado Filho, passando depois para uma sala na Avenida Venâncio Aires e, na sequência, na Rua Garibaldi, estabelecendo-se, definitivamente, na Rua Marquês do Pombal, no Bairro Auxiliadora. Anos mais tarde, em 1986, concluía uma segunda especialização em Diagnóstico Psicológico pela PUC-RS. Essa segunda especialização conduziria, em muito, seus trabalhos futuros, tendo sido coordenadora, mais adiante, desse mesmo Curso de Especialização em Diagnóstico Psicológico na PUC-RS. Foi durante A execução do Curso, como aluna, que conheceu a Profa. Dra. Jurema Alcides Cunha, com quem veio a trabalhar muitos anos, bem como com sua equipe de trabalho, que se transformaram em grandes amigas.

Com a vida profissional e afetiva encaminhadas, iniciou, em 1986, como professora auxiliar, com uma carga horária de 8 horas-aula na PUC-RS. De 1988 a 1994 era docente também na Universidade do Vale do Rio dos Sinos (Unisinos). Sua formação teve em sequência um curso de Mestrado em Psicologia Social e da Personalidade pela PUC-RS (1991), sob orientação da Profa. Dra. Jurema Alcides Cunha (ícone na área da Avaliação Psicológica), cuja dissertação intitula-se Conflito Edípico num Contexto Sociocultural do Século XX, e um curso de Doutorado em Ciências Médicas/Saúde Mental pela Universidade Estadual de Campinas - Unicamp (2001). No doutorado foi orientada por Neury José Botega, importante pesquisador do comportamento suicida até os dias de hoje. Sua tese versou sobre a Entrevista Semiestruturada para Autópsia Psicológica (ESAP) e, com isso, iniciou seus estudos sobre comportamentos violentos, tema que deu início, junto à validação de testes psicológicos, ao seu grupo de pesquisa intitulado Avaliação e Intervenção do Funcionamento Psicológico Adaptado e Não Adaptado, na PUC-RS, no ano de 2001.

Nesse caminho percorreu muitas conquistas pessoais e profissionais. Entre as profissionais, foi Bolsista 
Produtividade em Pesquisa do Conselho Nacional de Desenvolvimento Científico e Tecnológico (CNPq) no período de 2006 a 2013; Membro do Grupo de Trabalho para implantar uma Estratégia Nacional de Prevenção ao Suicídio do Ministério da Saúde/Brasil, no período de 2006 a 2008; Professora Titular da Faculdade de Psicologia da PUC-RS e Diretora da Faculdade de Psicologia da PUC-RS no período 2005 a 2009.

Ainda no campo profissional, na área da Avaliação Psicológica, a qual merece todas as nossas considerações por seus feitos, participou, no Conselho Federal de Psicologia (CFP) como integrante na Comissão Consultiva em Avaliação Psicológica desde o ano de 2005. Compareceu à sua última reunião da Comissão em 4 de outubro de 2013, pouco antes de falecer, na qual foi homenageada pela diretoria do CFP pelos relevantes serviços prestados à Comissão. Além da contribuição com as atividades da Comissão, Blanca colaborou com o CFP em diversos trabalhos. Entre eles, participou como palestrante, no dia 24 de julho de 2013, de um debate online sobre o suicídio na sede do Conselho com o tema "Uma questão de saúde pública e um desafio para a Psicologia clínica”. O debate teve grande número de acessos - quase 4 mil pontos conectados ao vivo $^{1}$. Fruto desse debate, em 18 de dezembro de 2013, o CFP lançou, na sede do Conselho Regional de Psicologia do Rio Grande do Sul (CRPRS), o livro intitulado "Suicídio e os Desafios para a Psicologia", contendo um dos últimos textos escritos por Blanca.

Num percorrido por sua formação e na formação de pessoas, Blanca tinha experiência na área de Psicologia Clínica, e suas pesquisas davam ênfase em Fundamentos e Medidas da Psicologia (Construção e Validação de Medidas Psicológicas) e Tratamento e Prevenção Psicológica. Tendo atuado, principalmente, nos seguintes temas: Desenvolvimento e Adaptação de Instrumentos de Avaliação e Intervenção Clínica e em Comportamentos Violentos (violência interpessoal, coletiva, autoinfligida e eventos catastróficos).

No ápice de sua carreira profissional, em meio a uma série de produções intelectuais e projetos futuros, entre eles planos para a realização de Pós-Doutorado na Espanha, em 2009, Blanca inicia o tratamento para um câncer. Brava, heroína, preferiu seguir seu trabalho em conjunto ao tratamento, isso enquanto foi possível.
Seu legado para a Psicologia é inquestionável e de extrema relevância, sendo suas principais contribuições para a área da Avaliação Psicológica os testes projetivos. Blanca dedicou-se ao Teste das Fadas, ao Teste de Apercepção Familiar (FAT), e ao Teste das Relações Objetais de Phillipson (TRO). Todos sabemos das dificuldades de se trabalhar com as técnicas projetivas e isso "nos fala" um pouco mais sobre ela. Como diretora, professora titular e professora pesquisadora no Programa de Pós-Graduação da Faculdade de Psicologia da PUC-RS, Blanca esteve à frente de seu tempo. Além disso, foi membro da Associação Brasileira de Rorschach e Métodos Projetivos (ASBRo), e do Instituto Brasileiro de Avaliação Psicológica (IBAP).

Sua contribuição para os programas de prevenção na área do suicídio do Ministério da Saúde, no qual foi membro do grupo de trabalho para implementação da Estratégia Nacional de Prevenção ao Suicídio, também é imensurável. Com este trabalho quebrou-se, em parte, o tabu sobre a temática do suicídio. Progressos de grande importância foram conquistados e a equipe responsável pela Estratégia Nacional de Prevenção do Suicídio colaborou na organização da Publicação das Diretrizes Nacionais para Prevenção do Suicídio.

- Criação da logomarca Amigos daVida que identifica a Estratégia Nacional de Prevenção do Suicídio.

- Realização do I Seminário Nacional de Prevenção do Suicídio, nos dias 17 e 18 de agosto de 2006, em Porto Alegre.

- Lançamento do Projeto ComViver, que oferece acompanhamento para parentes de pessoas que cometeram suicídio.

- Lançamento do Manual de Prevenção do Suicídio para Profissionais das Equipes de Saúde Mental.

- Lançamento da publicação Referências Bibliográficas Comentadas sobre Suicídio, Sobreviventes e Família.

- Lançamento do DVD do I Seminário de Prevenção do Suicídio com todas as apresentações dos pesquisadores e gestores que participaram do evento.

Blanca desenvolveu 69 artigos publicados em periódicos nacionais e internacionais, nove livros publicados e organizados, entre eles: Atualizações em Métodos Projetivos para Avaliação Psicológica, Avaliação Psicológica: Diretrizes na Regulamentação da

${ }^{1}$ Disponível em: https://www.youtube.com/watch?v=epjhgKhOu9g. 
Profissão, Temas em Psicologia Clínica, Psicanálise e Universidade: potencialidades teóricas no cenário da pesquisa; além de mais de 50 capítulos em livros de grande expressão e relevância. Em especial o livro Comportamento Suicida, publicado pela Artmed, que discorre sobre aspectos psicológicos, psiquiátricos, históricos, religiosos, sociológicos, epidemiológicos, bioéticos e de pesquisa para a compreensão e a prevenção de comportamentos suicidas, de forma simples e consistente.

Para além das suas últimas pesquisas envolvendo a validação dos testes já aludidos, Blanca participou dos estudos e da organização dos manuais do Inventário de Expectativas e Crenças Pessoais Acerca do Álcool (IECPA), do Teste Wisconsin de Classificação de Cartas: Versão para Crianças e Adolescentes, do Inventário de Depressão de Beck - BDI-II e do Teste Wisconsin de Classificação de Cartas: Versão para Idosos. Todos esses trabalhos foram em parceria com outros pesquisadores de grande expressão da área da avaliação psicológica.

Ao longo de sua carreira acadêmica, a Profa. Blanca participou de dezenas de bancas examinadoras. Nesse total estão computados os níveis de trabalho: professor titular, concurso público, doutorado, mestrado, qualificação de doutorado e mestrado, entre outros. Como orientadora, supervisionou 62 trabalhos até o ano de 2013, sendo eles: teses de doutorado, dissertações de mestrado, trabalhos de conclusão de curso graduação e atividades de iniciação científica.

Blanca investiu muito na sua carreira de pesquisadora. Encontrava-se em uma etapa da vida onde o reconhecimento dos seus trabalhos em pesquisas e outros trabalhos técnicos eram de âmbito nacional e internacional, recebendo muitos convites para conferências e abertura de eventos importantes. Desenvolveu 12 projetos de pesquisa até o ano de 2013. Seu enfoque foi no Desenvolvimento e Adaptação de Instrumentos e Estratégias de Avaliação e Intervenção Clínica. Os enfoques de trabalho escolhidos foram destinados para o profissional da área da Psicologia, visto que um dos principais desafios que tinha era a realização de avaliações e intervenções clínicas de forma segura e profunda, a respeito do sujeito que estava sendo avaliado. Nesse sentido, o objetivo dessas linhas de pesquisa era a adaptação de instrumentos e estratégias à realidade brasileira, com complexos estudos de fidedignidade e validade com grandes amostras de grupos clínicos e com sujeitos da população geral, de diferentes Estados do País.

Outra linha de pesquisa desenvolvida foi Manifestações psicológicas decorrentes de violência autoinfligida, interpessoal, coletiva e de eventos catastróficos. O objetivo dessa linha era compreender e identificar fatores psicológicos que levam uma pessoa a tirar sua própria vida, a de outra, maltratar, abusar, se envolver em confrontos, acidentes, comportamentos de risco, provocando traumas internos e externos; e decorrem de situações que ameaçam a integridade física e emocional das pessoas. Os estudos nessa área concentravam-se em aspectos como: ideação suicida, tentativa de suicídio, suicídio, homicídio seguido de suicídio, homicídio, violência doméstica, violência intrafamiliar, abuso sexual, assaltos, sequestros, desastres naturais, terrorismo e eventos catastróficos.

Até o ano de 2013, Blanca havia ministrado cerca de 40 disciplinas, distribuídas entre graduação, cursos de Especialização, Mestrado e Doutorado. Os conteúdos, sempre voltados para a área clínica, variavam em Psicopatologia, Psicopedagogia Terapêutica, Psicologia Clínica, Supervisão de Estágio em Psicologia Clínica, Psicodiagnóstico, Técnicas Projetivas, Técnicas e Métodos em Pesquisa, entre outros.

$\mathrm{Na}$ esfera "pessoal" e afetiva, Blanca recebeu inúmeras homenagens, reconhecimentos e agradecimentos por parte de colegas, alunos e orientandos. No âmbito acadêmico, teve o reconhecimento pelos 25 anos de atividade profissional na PUC-RS, recebendo a medalha Irmão Afonso, em 2011. Além disso, em 1999 conquistou o Primeiro Lugar na Sessão de Pôsteres, no VIII Congresso Nacional de Avaliação Psicológica; em 2010 recebeu Menção Honrosa - Premio Capes de Teses 2009, Coordenação de Aperfeiçoamento de Pessoal de Nível Superior (Capes); em 2011 teve Agradecimento Especial e Humanístico no Centro de Valorização da Vida (CVV); e em 2012 recebeu Primeiro e Segundo lugares na Sessão de Pôsteres junto à Associação Brasileira de Rorschach e Métodos Projetivos com os respectivos trabalhos Teste de Apercepção Familiar - FAT: Estudo Preliminar sobre Respostas Populares e Depressão, Desesperança e Potencial Suicida em Mulheres Vítimas de Violência Doméstica.

Ainda que seja impossível esgotar seus feitos, conforme pôde ser revisto, Blanca teve um importante papel na Psicologia no Brasil. Suas lembranças enquanto pessoa e profissional ficarão na memória de todos nós, para além do compromisso de seguir seu legado. 
Ao longo desse artigo, escrito a oito mãos, além de revisitarmos a trajetória pessoal e profissional da nossa querida Blanquita, lançamos mão de muitas memórias afetivas. Cada uma de nós, em separado, mas também, conjuntamente, temos muitas vivências e muitas histórias que, certamente, renderiam muitas páginas. Assim, ficam aqui nosso respeito, admiração e saudades eternas.

\section{Fontes de informação}

Airton Mazzuca Werlang e amigas. CV: http://lattes. cnpq.br/4359314519551153

Oliveira, M. S. (2015). In memorian profa. Dra. Blanca Susana Guevara Werlang (15/10/1955 -15/11/2013). Boletim de Psicologia, 65(142), 115-118.

\section{Clarissa Marceli Trentini}

Psicóloga.Doutora emCiências Médicas:Psiquiatria (UFRGS). MestreemPsicologia(PUCRS). EspecialistaemAvaliação Psicológica (UFRGS). Professora dos Cursos de Graduação e Pós-Graduação (UFRGS). Bolsista de Produtividade em Pesquisa CNPq, nível 1D. e-mail: HYPERLINK “mailto:clarissatrentini@terra.com.br” clarissatrentini@terra.com.br

\section{Samantha Dubugras Sá}

Psicóloga Clínica. Doutora em Psicologia (PUCRS). Mestre em Psicologia Clínica (PUCRS). Possui Pós Graduação em Atenção Integral a Vítimas de Violência pela Universidade Complutense de Madri (UCM). Professora Adjunta do Curso de Psicologia da Escola de Ciências da Saúde (PUCRS). E-mail: HYPERLINK “mailto:samantha.sa@pucrs. br"samantha.sa@pucrs.br

\section{Margareth da Silva Oliveira}

Psicóloga. Pós Doutora na University of Mariland Baltimore County (UMBC-USA). Doutora em Psiquiatria e Psicologia Médica (UFSP). Mestre em Psicologia (PUCRS). Bolsista de Produtividade em Pesquisa CNPq, nível 1C. Professora Titular dos Cursos de Graduação e Pós-Graduação do Curso de Psicologia da Escola de Ciências da Saúde (PUCRS). Coordenadora do Grupo de Pesquisa Avaliação e Tratamento em Psicoterapia Cognitiva e Comportamental (PUCRS).E-mail: HYPERLINK “mailto:marga@pucrs.br” marga@pucrs.br

\section{Irani Iracema de Lima Argimon}

Psicóloga. Mestre em Educação (PUCRS). Doutora em Psicologia (PUCRS). Professora Titular no curso de Psicologia da Escola de Ciências da Saúde e Instituto de Geriatria (PUCRS). Coordenadora do Grupo de Pesquisa Avaliação e Intervenção no Ciclo Vital. E-mail: HYPERLINK “mailto:argimoni@pucrs.br” argimoni@pucrs.br

Endereço para correspondência Pontifícia Universidade Católica do Rio Grande do Sul, Curso de Psicologia, Programa de Pós-Graduação em Psicologia, Av. Ipiranga, 6681, prédio 11, $9^{\circ}$ andar, Partenon, Porto Alegre, RS, 90619-900. Tel.: (51) 3320 3500; Ramal: 7742; Fax: (51) 33203633.

Recebido 16/08/2018

Aprovado 16/08/2018

Received 08/16/2018

Approved 08/16/2018

Recibido 16/08/2018

Aprobado 16/08/2018 
Psicologia: Ciência e Profissão 2018 v. 38 (núm. esp.), 201-206.

Como citar: Trentini, C. M.; Dubugras Sá, S.; Oliveira, M. S.; Argimon, I. I. L. (2018). Blanca Susana Guevara Werlang (15/10/1955-15/11/2013): Um Pouco da História. Psicologia: Ciência e Profissão, 38(n.spe), $201-206$. https://doi.org/10.1590/1982-3703000211944

How to cite: Trentini, C. M.; Dubugras Sá, S.; Oliveira, M. S.; Argimon, I. I. L. (2018). Blanca Susana Guevara Werlang (15/10/1955-15/11/2013): A Little Bit of History. Psicologia: Ciência e Profissão, 38(n.spe), $201-206$. https://doi.org/10.1590/1982-3703000211944

Cómo citar: Trentini, C. M.; Dubugras Sá, S.; Oliveira, M. S.; Argimon, I. I. L. (2018). Blanca Susana Guevara Werlang (15/10/1955-15/11/2013): Un Poco de la Historia. Psicologia: Ciência e Profissão, 38(n.spe), $201-206$. https://doi.org/10.1590/1982-3703000211944 